\title{
Durability of responses in patients with metastatic renal cell carcinoma treated with high dose interleukin-2 (HD IL-2)
}

Joseph I Clark', Michael A Morse ${ }^{2}$, Michael KK Wong ${ }^{3}$, David F McDermott ${ }^{4}$, Howard L Kaufman $^{5}$, Gregory A Daniels ${ }^{6}$, Jessica C Perritt ${ }^{7}$, Hong Hua $^{7}$, Sandra Aung ${ }^{7 *}$

From 30th Annual Meeting and Associated Programs of the Society for Immunotherapy of Cancer (SITC 2015)

National Harbor, MD, USA. 4-8 November 2015

\section{Background}

HD IL-2 was FDA approved for advanced mRCC, but the data supporting its use dates to the 1990's. We designed the PROCLAIM ${ }^{\mathrm{SM}}$ registry, including retrospective and prospective cohorts, to study modern outcomes and interactions with prior or subsequent targeted therapies. We now report survival analysis from the Registry and the effect of prior TT therapy.

\section{Methods}

Inclusion criteria required patients receive at least one dose of IL-2. Survival for both cohorts $(\mathrm{N}=408)$ is current to March 16, 2015.

\section{Results}

The overall response rate (ORR) and mOS are described in Table 1. In the retrospective cohort, the 1,2 , and 3 year survival rates were $89 \%, 69 \%$, and $61 \%$ respectively for patients with stable disease (SD). Similarly, in the prospective cohort, 1 and 2 year survival rates for patients with SD were $95 \%$ and $76 \%$, respectively. The mOS was not reached for patients with SD in both cohorts. There was a significant difference in $\mathrm{mOS}$ between $\mathrm{SD}$ and $\mathrm{PD}$ patients in the prospective cohorts, NR vs 13.9 months, $\mathrm{p}<0.0001$, there was no significant difference in mOS between SD and PD in the retrospective cohort. For patients in the retrospective and prospective cohorts who had prior targeted therapy (TT), the mOS was 15.3 and 22.1 months, respectively. Patients who did not receive TT before HD IL-2 therapy, the mOS was 48.9 months and NR, in the retrospective and prospective cohorts, respectively. There were 4 treatment-related deaths in 408 patients.

\section{Conclusions}

PROCLAIM data demonstrate that SD, previously grouped with the non-responders, has extended survival

Table 1

\begin{tabular}{lcc}
\hline Updated March 16, 2015 & Retrsopective Cohort $(2007-2012) \mathrm{N}=97,11$ sites & Prospective Cohort $(2011-2015) \mathrm{N}=311,39$ sites \\
\hline mOS, months & 48 & $\mathrm{NR}$ \\
\hline Median follow-up, months & 43.8 & 18.7 \\
\hline $1,2,3$ year survival rate, CP/PR & $100 \%, 89 \%, 84 \%$ & $100 \%, 85 \%, 79 \%$ \\
\hline $1,2,3$ year survival rate, SD & $89 \%, 69 \%, 61 \%$ & $95 \%, 76 \%, n / \mathrm{d}$ \\
\hline ORR & $20 \%(C R: 5 \%$, PR: 15\%) & $16 \%(C R: 3 \%, P R: 13 \%)$ \\
\hline CR+PR+SD & $49 \%$ & $55 \%$ \\
\hline mOS no prioir TT/prior TT & $48.9(n=82) / 15.3(n=15)$ & $N R=266) / 22.1(n=45)$
\end{tabular}

${ }^{7}$ Prometheus Laboratories Inc., San Diego, CA, USA 
rates. TT prior to HD IL-2 therapy was associated with a lower mOS. These data support that HD IL-2 has favorable safety profile compared to data in the original package insert and remains an effective first line therapy for eligible patients with mRCC.

\section{Authors' details}

'Loyola University Medical Center, Division of Hematology Oncology, Maywood, IL, USA. ${ }^{2}$ Duke University Medical Center, Durham, NC, USA.

${ }^{3}$ University of Southern California, Los Angeles, Los Angeles, CA, USA. ${ }^{4}$ The Cytokine Working Group; Division of Hematology/Oncology, Beth Israel Deaconess Medical Center, Boston, MA, USA. ${ }^{5}$ Rutgers Cancer Center Institute of New Jersey, New Brunswick, NJ, USA. ${ }^{6}$ Moores Cancer Center, University of California San Diego, La Jolla, CA, USA. ${ }^{7}$ Prometheus Laboratories Inc., San Diego, CA, USA.

Published: 4 November 2015 metastatic renal cell carcinoma treated with high dose interleukin-2 (HD IL-2). Journal for ImmunoTherapy of Cancer 2015 3(Suppl 2):P225.

\section{Submit your next manuscript to BioMed Central} and take full advantage of:

- Convenient online submission

- Thorough peer review

- No space constraints or color figure charges

- Immediate publication on acceptance

- Inclusion in PubMed, CAS, Scopus and Google Scholar

- Research which is freely available for redistribution

Submit your manuscript at www.biomedcentral.com/submit 